\title{
Qualitative relationism about subject and object of perception and experience
}

\author{
Andrea Pace Giannotta ${ }^{1}$ \\ Accepted: 29 October 2020 / Published online: 9 November 2020 \\ (C) The Author(s) 2020
}

\begin{abstract}
In this paper, I compare various theories of perception in relation to the question of the epistemological and ontological status of the qualities that appear in perceptual experience. I group these theories into two main views: quality externalism and quality internalism, and I highlight their contrasting problems in accounting for phenomena such as perceptual relativity, illusions and hallucinations (the "problem of perception"). Then, I propose an alternative view, which I call qualitative relationism and which conceives of the subject and the object of perceptual experience as essentially related to one another (hence relationism) in a process of co-constitution out of fundamental qualities (hence qualitative relationism). I lend support to this view by drawing on Husserl's genetic phenomenology, which I complement with a form of neutral monism. I argue that the investigation of the temporal structure of perceptual experience leads us to find at its heart a qualitative process that is more fundamental than the two relata of perception and that gives rise to them. Then, I extend this account of perception into a general theory of intentionality and experience and I develop its implications into a neutral monist metaphysics.
\end{abstract}

Keywords Phenomenal consciousness · Qualia - Internalism and externalism · Perception · Phenomenology $\cdot$ Neutral monism $\cdot$ Phenomenal intentionality

\section{Introduction}

The starting point of this paper is the characterization of ordinary perception as involving a relation between the perceptual experiences of a subject and objects that

Andrea Pace Giannotta

andreapacegiannotta@gmail.com

1 Department of Humanities (DILEF), University of Florence, via della Pergola 58-60,

Florence 50121, Italy 
appear as independent from these experiences (or "mind-independent"). ${ }^{1}$ Furthermore, perceptual experiences present concrete qualitative features that are evident from the first-person perspective and that can be defined in the terms of "what it is like" (Nagel 1974) to have or to undergo them. ${ }^{2}$ For instance, perceiving a yellow lemon I undergo a perceptual experience that presents the lemon and the quality "yellow". Starting from this characterization of perceptual experience as directed at objects and as qualitative, one can ask about the nature of the qualities that appear in it, e.g. the "yellowness" when perceiving the lemon. Are they properties of mind-independent objects in the world? Or, on the contrary, are they merely subjective properties of mental states through which we possibly come to know a mind-independent world? Concerning this question, the various theories of perception that are debated in the literature can be divided according to two options: internalism and externalism. This distinction partially cross-cuts various theories of perception and allows us to capture differences and similarities between them that would otherwise be overlooked.

In the first two sections of this paper, I will discuss these two options, calling them quality externalism (sec. 1) and quality internalism (sec. 2). I shall highlight how each of these positions has contrasting difficulties when addressing the problems posed by perceptual relativity, illusions and hallucinations. These problems put pressure on these views and lead us to consider an alternative view, which I call qualitative relationism.

Qualitative relationism brings into question an idea that comes into play in both externalism and internalism: the idea that the sensory qualities that characterize perception are intrinsic properties of either mind-independent material objects (for quality externalism) or subjective experiences (for quality internalism). ${ }^{3}$ In sec. 3, I shall question this assumption in the light of the investigation of the temporality of experience, by drawing especially on Husserl's genetic phenomenology. In particular, I shall introduce a distinction between two different levels in the analysis of the temporal character of experience: macro-temporality and micro-temporality. I shall argue that, whereas when investigating the macro-temporality of experience we can refer to the relationship between perceptual states and objects and their respective properties, the investigation of micro-temporality reveals a qualitative process that is more fundamental than the two relata of perception and that gives rise to them. In this way, I will define qualitative relationism as the view according to which subject and object of perceptual experience are essentially related to one another (hence relationism) in a process of coconstitution out of fundamental qualities (hence qualitative relationism).

\footnotetext{
${ }^{1}$ However, the fact that perceptual objects seem to be mind-independent does not prove that they are, in fact, mind-independent.

${ }^{2}$ I am considering here instances of conscious perception, leaving aside the analysis of unconscious perceptual states. More in general, I am making use of the concept of "mind" in the sense of "conscious" or "phenomenal" mind (see Chalmers 1996), leaving aside the analysis of unconscious cognitive phenomena (e.g. dispositional states and unconscious mental processes in general). In the end, I will claim that the proposed account is able to account also for these phenomena.

${ }^{3}$ In fact, in order to account for phenomena such as illusions and hallucinations, externalists are lead to admit, together with qualitative properties of worldly objects, also qualities that are internal to the experience. However, they clearly separate these two kinds of properties (see sec. 2). Furthermore, naive realists conceive of perceptual states as constituted by the relation with external objects and their properties, but this is compatible with the claim that the qualitative properties of external objects are intrinsic to them and do not depend on the relation with a perceiver (see sec. 2).
} 
The focus of this paper is on the analysis of perceptual experience. However, I will stress the central role of this analysis in developing a theory of knowledge and metaphysics. This is because perceptual intentionality seems to be a fundamental form of directedness of the mind towards an "external world". ${ }^{4}$ For this reason, a philosophical theory of perception should say something about the relationship between "appearance" and "reality", "mind" and "world". When discussing the various theories of perception, I shall thus highlight their metaphysical presuppositions and/or implications. ${ }^{5}$ In line with this approach, I shall develop the qualitative relationist proposal in a metaphysical direction, by conceiving of it in terms of neutral monism: the metaphysical position according to which there is a fundamental reality whose intrinsic nature is neither mental (internal) nor physical (external) but neutral between the two. According to the proposal here developed, this fundamental reality consists of qualitative elements that are pre-phenomenal and pre-objectual and that, under certain circumstances, combine into those complex entities that we call subjects and objects.

\section{Quality externalism}

With "quality externalism" I refer to the idea that the qualities that appear in perception are properties of mind-independent objects "out there", in the external world. This view is shared by two of the main theories of perception: the standard version of naïve realism and the externalist version of representationalism (e.g. Dretske 1996, 2003; Tye 1995). ${ }^{6}$

Naïve realism is a form of direct realism that claims that in perception one is acquainted with objects in the environment and with their qualitative properties, such as colours, sounds, odours, etc. The standard version of naïve realism presupposes a distinction between act and object, which are directly related in perception. ${ }^{7}$ As an example of such a view, we can consider Gibson's ecological theory of perception (Gibson 1966, 1967, 1972). Gibson claims that perception consists in directly picking up information in the environment, in contrast to those views that appeal to internal sensations or sense-data (understood as mind-dependent entities). However, Gibson does not deny that we can have certain sensations, such as after-images or "ringings in the ears", which arise from the stimulation of sensory nerves and that appear in the "theater of consciousness" (Gibson, 1967: 163). These sensory impressions are similar to other bodily sensations such as pains and itches, which do not seem to pertain to

\footnotetext{
${ }^{4}$ My primary focus here is on sense perception and I am not considering other forms of directedness towards something that seems to be "external" to the experience of a subject, such as empathy, moral perception, or mathematical intuition.

${ }^{5}$ We will see that in some cases a theory of perception presupposes a certain metaphysics, whereas in other cases it possibly implies it.

${ }^{6}$ A form of quality externalism is also implied by those versions of the sense-data theory that conceive of them as non-ordinary but mind-independent objects.

${ }^{7}$ However, a radical version of this theory conceives of the relation between act and object in terms of identity. This is the view developed by neutral monists such as Mach and James. The latter claims, for example, that in perceptual experience perceiver and perceived "fuse" or "merge" (see Stubenberg 2018: 14). This form of naïve realism is no longer externalist, since it questions the very distinction between internal and external. I will come back to this view in sec. 4. From now on, with "naïve realism" I will refer to the externalist version, which presupposes the act-object distinction.
} 
mind-independent objects in the world. However, according to Gibson, these phenomenal features of experience do not have any role in perception and are distinct from those qualities that appear in perceptual experience, such as the colours of worldly objects (Gibson 1967: 162; 1972: 77). In perception, we are directly aware of the qualities of objects in the environment and not of private sensations. Gibson develops this view as a vindication of common-sense realism (Gibson 1967) and therefore of the idea that perception gives us direct access to a mind-independent and qualitative world. $^{8}$

Naïve realism is also sometimes referred to as "relationalism", because it conceives of the perceptual act as constituted by the relation with the mind-independent object. In this sense, naïve realism conceives of the subjective pole of the perceptual relation as not independent from the object to which it is directly related. For example, the act of perceiving a red tomato is constituted by the relation with the tomato. However, this standard version of naïve realism also conceives of the object as mind-independent and as endowed with objective properties that are not dependent on the perceptual relation. For this reason, in the standard formulation, naïve realism is a form of externalism regarding qualities. ${ }^{9}$

Another form of quality externalism is the externalist version of representationalism proposed, amongst others, by Dretske $(1996,2003)$ and Tye (1995). In contrast to naïve realism, representationalist theories of perception claim that the relationship between perceiver and environment is mediated by mental representations, i.e. informationbearing structures that have a certain intentional content, through which they represent things as being in a certain way. The externalist version of representationalism claims that, whereas the vehicle of mental representation is internal to the cognitive system, its phenomenal content is "external" or "wide". In line with the externalist theory of meaning, according to which meaning is not "in the head", according to Dretske's "phenomenal externalism" (Dretske 1996), also "qualia" are not in the head, being external contents of representational states. ${ }^{10}$

\subsection{The problem of perception regarding quality externalism}

Naïve realism (in the standard, externalist version) and externalist representationalism claim that the qualities that appear in perception are mind-independent properties of objects in the world. However, these forms of externalism regarding qualities are challenged by the phenomena of perceptual relativity, illusion, and hallucination.

\footnotetext{
$\overline{8}$ These implications of Gibson's theory of perception are drawn for instance by B. Smith $(1995,1999)$ within the project of a "qualitative ontology" (see Petitot and Smith 1997). In this view, sensory qualities are objective properties of mind-independent objects in the world. However, it is also possible to understand Gibson's theory within a neutral monist framework, which conceives of the relation between act and object in perception as an identity relation. See Heft (2001), who links Gibson's view to the neutral monism of James (1912).

${ }^{9}$ This is especially clear when naïve realism is combined with disjunctivism in order to account for the problem of perception (see below, sec. 2.1).

${ }^{10}$ Gow (2018: 5 ff.) stresses the fact that, by conceiving of qualities as external properties of mindindependent objects, externalist representationalism turns out to be very close to naïve realism. Concerning the relationship between externalist representationalism and metaphysics, Dretske conceives of his proposal as a way of "naturalizing the mind" (Dretske 1995), thus finding its place in the natural world.
} 
For example, the colour of a visual object varies with changes in the environmental or psychological viewing conditions (intrapersonal relativity), among different perceivers of the same species (interpersonal relativity) and among different types of animals (interspecies relativity; see Cohen 2004). The phenomenon of perceptual relativity leads us to question the idea that qualities such as colours are intrinsic properties of objects in the environment. Also perceptual illusions lead us to question the external status of sensible qualities. For example, by looking for some time at an orange lamp and then at a white wall, one experiences a blue after-image. In this case, the quality "blueness" seems to be a mental (experience-dependent) property and not an objective property of the wall. Hallucinations constitute an even harder challenge for externalism since they are indistinguishable from veridical perception and purport to present objects which, however, do not exist at all outside the experience.

These phenomena lead to the distinction, which is central to quality internalism, between phenomenal appearance, which can also be illusory or hallucinatory, and objective reality.

However, in order to maintain the idea that sensible qualities are mind-independent properties of objects in the world, both naïve realism and externalist representationalism can be joined with disjunctivism. According to disjunctivism, even if veridical perception and hallucination are subjectively indistinguishable, they are different kinds of mental states: in the "good case" one is acquainted with qualitative properties of external objects, whereas in the "bad case" one has a different kind of experience, which involves mind-dependent qualities.

The disjunctivist view is endorsed especially by naïve realists. However, also externalist representationalism turns out to be committed to disjunctivism (Gow 2018; see also Williford 2013: 514). For example, Dretske claims that "typically" (Dretske 2003: 68) the qualitative properties that objects are represented as having are external and objective. This leaves open the possibility that in non-usual cases the phenomenal contents of representational states have a different nature. In fact, Dretske seeks to account for cases of non-veridical perception in terms of misrepresentations, which occur when representational states fail to refer correctly to an object, as in the case of a malfunctioning thermometer that misrepresents temperature. However, in the case of phenomenal mental states, the analogy with a physical instrument, such as the thermometer, does not fully work (see Mcintyre 1999: 436), as the measure of temperature by the thermometer is merely quantitative and not qualitative - it does not have any associated "what-it's-likeness". On the contrary, when externalist representationalism tries to account for the referential failure of perceptual states, which have a phenomenal content, it is led to admit an internal phenomenal content of the misrepresenting state. If I misrepresent a tomato as being blue instead of red, because my experience is altered by the ingestion of a psychedelic drug, the "blueness" must be an internal phenomenal content of my mental state. This is even more clear in the case of hallucinations. If one wants to give a positive account of them, and not just a negative one, one has to appeal to internal phenomenal contents of representational states. However, when doing so, externalist representationalism turns out to be very close to quality internalism (see Williford 2013: 514).

Naïve realism also finds analogous problems when appealing to disjunctivism in order to account for the problem of perception. For example, considering again Gibson's view, endorsing disjunctivism would mean blurring the distinction that it 
makes between sensory impressions (internal and not entailed in perception) and qualitative properties of external objects (directly perceived). In the "bad case", what seems to be an objective property is, in fact, an internal phenomenal appearance.

So, in order to account for the problem of perception, both naïve realism and externalist representationalism are led to endorse disjunctivism. This implies commitment to an internalist account of illusions and hallucinations, admitting that the sensory qualities involved in these cases are merely internal phenomenal contents of mental states. However, at this point, an objection is that the same internalist account could be employed to account for veridical perception, claiming that in it we are also acquainted with merely internal phenomenal appearances. In particular, when trying to give a positive account of hallucinations, the disjunctivist can appeal to physical processes in the brain, conceived of as the proximal cause of the hallucinatory experience, but the same account can be also applied to the veridical case, and this would make the reference to mind-independent qualities in the veridical case unmotivated. This objection puts pressure on quality externalism, pointing at the difficulty in maintaining a purely externalist account of sensory qualities and offering a reason for considering the opposite view, i.e. quality internalism. ${ }^{11}$

\section{Quality internalism}

With "quality internalism", I refer to the idea that the qualities that appear in perception are "internal" to the experience of a subject. A significant motivation for this position is the possibility of unitarily accounting for perceptual relativity, illusion and hallucination, claiming that the sensory qualities that appear in these experiences are properties of conscious mental states and not mindindependent properties of external objects. Quality internalism, therefore, makes use of a distinction between phenomenal appearance, "in the mind", and mindindependent reality. ${ }^{12}$ This view can be found in various theories of perception: the standard version of the sense-data theory; adverbialism; and those internalist versions of representationalism that admit the existence of qualia.

In particular, I would like to take a close look at a recent development of just such an internalist view of qualities, in the so-called phenomenal intentionality theory (PIT). At the heart of this view, there is the criticism of separatism (Horgan and Tienson 2002: 520 ), which consists in treating phenomenal consciousness and intentionality as posing two distinct problems for the philosophy of mind. The central claim of PIT is that

\footnotetext{
${ }^{11}$ I am not claiming that this is a wholly conclusive reason for abandoning quality externalism but that it constitutes a difficulty of this view and a reason for considering other options. In fact, disjunctivists attempt to answer this kind of objection in various ways (for an overview see Crane and French 2017). Suffice for me to highlight here the difficulties in the externalism regarding qualities and, in the next section, leverage the arguments from the opposite view, i.e. quality internalism. In the end, my aim is to show that qualitative relationism is another, overlooked option that better addresses the issues at stake.

12 Again, I am using here the term "mind" in the sense specified above, i.e. as "conscious" or "phenomenal" mind.
} 
phenomenality and intentionality are essentially linked to one another, as the original form of intentionality is grounded on "phenomenology". 13

PIT is a general theory of intentionality, which seeks to account for the directedness of mental states towards objects in terms of phenomenal consciousness (i.e. in the terms of their "what-it's-likeness"). However, the analysis of perceptual intentionality has a central role in this view, since perception is our fundamental form of directedness to an (allegedly) "external world". In fact, the main arguments in support of PIT are based on the analysis of perceptual intentionality. These arguments lead to the claim that intentional states represent objects in virtue of a phenomenal content that is narrow (i.e. internal, as opposed to "wide" or "external"). ${ }^{14}$ This claim is motivated by the logical conceivability of scenarios that involve the duplication of a conscious being's experience - "logical conceivability" meaning that these possibilities, for essential reasons, cannot be ruled out a priori. One can conceive of the exact duplication of a phenomenal experience, whereas the corresponding world "outside" the mind is very different. Indeed, I can conceive of a "phenomenal duplicate" that possesses phenomenal states that are identical to mine but, for example, lives on Twin Earth, is deceived by an evil demon, or has been raised as a brain in a vat (Farkas 2008; see also Horgan and Tienson 2002; Loar 2003; Horgan, Tienson, and Graham 2004; Kriegel 2007).

The logical conceivability of phenomenal duplicates supports the thesis that the phenomenal content of intentional states logically supervenes on the subject's internal states and not on "external" factors, thus being "narrow". Kriegel defines the narrowness of phenomenal intentionality in terms of non-relationality: "an intentional property is narrow just in case it supervenes on the subject's non-relational properties, that is, is 'locally supervenient."' (Farkas 2013: 5). This means that the phenomenal properties of a mental state (e.g. the yellowness in perceiving a ripe lemon) are intrinsic or monadic properties, i.e. non-relational features of mental states that are not constitutively dependent on the existence of an external object.

Now, I would like to highlight a problem in this view: in the definition that we have just seen, it is not clear what is meant by "internal" and "local". In fact, it is common to make a distinction between "internal" and "external" by referring to the boundaries set by the skin or the brain of a minded creature, thus presupposing the existence of entities such as brains and bodies. However, this is a metaphysical assumption that should not be taken for granted when defining internalism (see Farkas 2003). In fact, the paradigm of an internalist position is in Descartes (2008), who develops it as an epistemological inquiry that leads to a dualist metaphysics. Descartes's internalist argument consists in claiming that the first-person investigation of experience shows, first of all, only the

\footnotetext{
${ }^{13}$ The central claim of PIT is that there is a basic form of intentionality that is grounded on phenomenal consciousness. Then, different versions of this view differ in how they account for the relationship between basic (or "source") intentionality and other, derivative, forms of intentionality, ranging from weak versions to strong versions of PIT (according to which all intentionality is phenomenal). There is also an ongoing debate concerning the extent of phenomenal intentionality, e.g. concerning the distinctive phenomenology of thinking ("cognitive phenomenology"), the phenomenology of agency, etc. See Kriegel (2013); Bourget and Mendelovici (2017) for an overview.

${ }^{14}$ Concerning the role of the analysis of perception in PIT, the usual way of conceiving this view is in the terms of an internalist form of representationalism, in contrast to the externalist representationalism of e.g. Dretske and Tye (see sec. 2). Kriegel (2007) proposes this view as a generalization to all representations of the adverbial account of sense perception. At the same time, PIT can also be likened to an internalist version of the sense-data theory.
} 
existence of subjective experience. It is through further argumentation that Descartes can overcome solipsism and reach the dualist conclusion (by appealing to the innate idea of a God that cannot deceive).

One must therefore distinguish, from amongst the arguments in support of PIT, between the logical conceivability of a "brain in a vat" (whose internal states supervene on the physical states of the brain, thus presupposed) and the logical conceivability of a disembodied mind, with no relation to an external world. ${ }^{15}$ The latter possibility is admitted by Kriegel, who claims that one can conceive of a "soul, floating through otherwise empty space but (by sheer luck) undergoing conscious experiences that are phenomenally indistinguishable from yours" (Kriegel 2007: 321). In this example, if one drops the reference to the indistinguishability of these experiences to those of an embodied subject, what is left is the conceivability of a disembodied soul, i.e. a solus ipse.

\subsection{The problem of perception regarding quality internalism}

Therefore, PIT is a form of internalism concerning the qualities of perception. ${ }^{16}$ Its main advantage over quality externalism is that it can account for veridical perception, illusion and hallucination, by conceiving of all these states as representational states endowed with an internal phenomenal content. However, taking the internalist stance to its logical conclusion leads us to raise the classic skeptical point: is there an external world at all that corresponds to those experiences that purport to refer to mindindependent objects? How can I know that I am not a solus ipse? Concerning the analysis of perception, this is the problem when accounting for the difference between veridical perception, that purports to refer to mind-independent objects, and experiences such as dreams and hallucinations.

This issue is made explicit by Chalmers when considering a form of quality internalism in his (Chalmers 1996). Chalmers raises "Descartes's problem about the existence of the external world" (Chalmers 1996: 75), which is due to the fact that "It is compatible with our experiential evidence that the world we think we are seeing does not exist; perhaps we are hallucinating, or we are brains in vats." (Chalmers 1996: 75). I stress again that the brain-in-a-vat hypothesis still presupposes the existence of a mindindependent brain. Strictly speaking, on the same basis, it is possible to claim that experiential evidence is compatible with the possibility that "I am a solus ipse". According to Chalmers, the internalist can simply quell the skeptical doubts with an inference to the best explanation (Chalmers 1996: 75), but "the in-principle possibility that we are wrong remains" (Chalmers 1996: 75). The same kind of issue is raised by various proponents of PIT. Farkas (2013: 108) claims that her account of phenomenal intentionality is situated "on the phenomenal level" and that it is compatible with the possibility that one is a brain in a vat, because "an embodied person and his brain-in-avat Doppelgänger share narrow contents possessing phenomenal intentionality" (Farkas 2008: 285). Farkas also turns from the brain-in-a-vat hypothesis to the idealist

\footnotetext{
$\overline{15}$ These two cases are often conflated in the literature. For instance, Horgan and Tienson (2002: 524) tell us to imagine a phenomenal duplicate that is "a brain in a vat or a disembodied Cartesian mind".

${ }^{16}$ As I have already claimed, PIT can be taken as representative of various versions of quality internalism such as the standard (internalist) version of the sense-data theory, adverbialism, and internalist representationalism.
} 
hypothesis, admitting that her view is compatible with idealism, even if she does not endorse it (Farkas 2013: 114 fn. 6).

The compatibility with subjective idealism or solipsism does not constitute a conclusive reason to abandon quality internalism. The internalist can argue that we must live with this possibility and that, nevertheless, quality internalism is still the best theory that is available. However, this problem puts pressure on this view and gives a reason for searching for an alternative position, which would not give rise to the sceptical hypothesis. It is precisely this alleged advantage over quality internalism that is claimed by proponents of naïve realism, whose thesis that we are in direct contact with mind-independent objects should dismantle the sceptical scenarios. For example, Gibson claims that a virtue of his theory of direct perception is that it avoids the "ridiculous pit of solipsism" (Gibson 1967: 171). However, as I have argued (sec. 2.1), when trying to account for the problem of perception, both naïve realism and externalist representationalism become very close to quality internalism and this means that they cannot really rule out the solipsistic hypothesis.

\section{Qualitative relationism}

At this point, we can see that each of the two options concerning the nature of sensory qualities - internalism and externalism - play on the difficulties of the other when addressing the problem of perception. This opposition between two views motivates the search for an alternative that can address their respective difficulties.

I shall now argue that qualitative relationism is the alternative sought. In particular, qualitative relationism brings into question an idea that is shared, in different ways, by quality externalism and internalism: the idea that sensory qualities are intrinsic properties of either conscious mental states or external objects - an intrinsic property being possessed by one of the two poles of the perceptual relation, regardless of the relation with the other. In fact, externalism and internalism take, as a starting point, the view of perception as a relation that presupposes two poles: conscious mental state and object. Subsequently, they conceive of the qualities as properties that pertain to one of the two poles of this relation, independently of the other. ${ }^{17}$ Qualitative relationism questions this starting point by showing that it pertains to a preliminary level of inquiry that is confined to the investigation of the macro-temporal structure of experience. I will now argue that, by "deepening" this inquiry, we can conceive of qualities as primal elements out of which internal qualitative properties of mental states and external qualitative properties of objects, i.e. the two poles of the perceptual relation, are co-constituted in reciprocal dependence. ${ }^{18}$

In order to motivate this view, we must now consider the temporal nature of experience. In fact, even if we usually refer to mental states and objects as if they were static entities with a certain set of properties, they are processes that unfold over time. In particular, we can investigate the temporal nature of experience within two

\footnotetext{
${ }^{17}$ As I have argued, this applies also to the standard version of naïve realism which, at least concerning veridical perception, conceives of qualities as objective properties of mind-independent objects, at the same time taking into account illusions and hallucinations in terms of internal qualities of mental states.

${ }^{18}$ I will elaborate on this concept of co-constitution below.
} 
different levels of analysis, by focusing on its macro-temporal or its micro-temporal structure. With these expressions, I refer to the difference between a coarse-grained analysis of the temporality of experience - e.g. when considering a succession of experiences in perceiving a tomato from various points of view - and a finer-grained analysis of the inner temporality of each moment of the experiential process - e.g. when considering single moments in the perception of the tomato "now".

\subsection{Macro-temporality and phenomenal intentionality as constitution}

The investigation of experience in its macro-temporal structure comes into play especially in the phenomenal intentionality view. In fact, one can consider the intentionality of "mental states" in somewhat static terms, in analogy to the representational character of e.g. signs and pictures, which "stand for" something else. In this abstract consideration, propositional attitudes such as "John perceives the lemon" (or, also, "John thinks about Pythagoras' theorem", which means that he is consciously thinking about it) are intentional states. However, upon closer investigation this turns out to be an abstraction, as perceiving, thinking, imagining, desiring, etc. are processes that happen over time, i.e. they have a conscious duration. In fact, all these mental processes are temporal and, insofar as they are conscious, they have a phenomenal character, i.e. there is something it is like to have or to undergo them.

This point is stressed by the first proponents of PIT. Horgan and Tienson note that "Experience is not of instants; experience is temporally thick." (Horgan and Tienson 2002: 521) and Loar highlights the "compelling intuition" that mental life is "a stream of conscious thoughts, feelings and perceptions." (Loar 2003: 293) at the same time noting that, however, "Conceptions of mental content in the analytic tradition have tended to be phenomenologically impoverished, largely because of the emphasis on language and reference." (Loar 2003: 292-293). This means that phenomenal intentionality has a temporal structure. In particular, the investigation of this temporal structure comes into play in the way that some proponents of PIT seek to account for the relationship between perceptual states and their intentional objects, by making use of the notions of constitution and construction.

For instance, Farkas (2013) claims that perceptual states, which seem to be directed at something beyond themselves, do that in virtue of having a certain structure, thanks to which they "construct" an external world. According to Farkas, the other-presenting character of perceptual intentionality comes from the relations between phenomenal contents which, in themselves, are not presentational (Farkas 2013: 110). When certain phenomenal qualities come to be structured in a certain way, "the impression of an external world emerges" (Farkas 2013: 110). This otherpresenting structure of perceptual intentionality is missing in other kinds of experiences, such as pain. This leads Farkas to distinguish between the mere sensation (e.g. the sensation of red when experiencing an afterimage) and the "same sensational feature" (Farkas 2013: 113) in the presentation of an external object, e.g. in seeing a red tomato. The difference between the two cases is in the structure of the experience and not in the phenomenal content, which is the same. I stress the fact that, in this account, the structure in question is the macro-temporal structure of a series of experiences, which gives rise to perceptual intentionality, conceived of as a relation between mental acts and objects. 
Also Masrour (2013) develops PIT in order to account for the intentionality of perceptual experience, which is "other-presenting" and has "phenomenal objectivity" (Masrour 2013: 116). In particular, he develops a Kantian account of the "constitution" of the objects of perception based on phenomenal intentionality. According to Masrour, mental representations that have an internal phenomenal content acquire objective significance "in virtue of necessary temporal connections between them" (Masrour 2013: 120). Masrour's Kantian thesis is that perceptual experience acquires phenomenal objectivity in virtue of having a structure called "schematic dynamical unity" (Masrour 2013: 122 ff.). When a series of experiences has this structure it is schematically unified and the object is constituted.

In both Farkas and Masrour, we find confirmation in the idea that perceptual intentionality has a certain temporal structure that accounts for how narrow contents of experiences come to constitute allegedly "external" objects. This is a diachronic structure that concerns the relationship between series of experiences, which come one after the other in an experiential course and are somehow linked together. In this approach, it is the temporal connection between the experiences that leads to the constitution of the intentional correlate, whereas the singular experience is confined to the momentary "now". In this way, perceptual intentionality turns out to be a feature of series of experiences which, in turn, are taken as partial moments of the experiential flow.

At this point, I would like to compare these accounts of perceptual intentionality in terms of constitution of objects, in PIT, with Husserl's phenomenology of perception. In fact, Husserl too conceives of perception as a process of constitution, understanding this process in terms of a combination of intentionality (form) and quality (matter). According to Husserl, the intentional structuring of qualities leads to the constitution of the object as the correlate of perception. In this view, we must distinguish between the internal contents of perceptual experiences, e.g. continuously changing colour sensations, and the properties of the perceptual object, e.g. its colour (see Husserl 1983: 74-75). This means that, with the term of a quality such as "red", we can refer, at the same time, to the sensations of redness, which are internal contents, and to the redness of the tomato, which is an objectual property: the latter are constituted by means of the intentional structuring of the former. According to Husserl, an advantage of this theory is that it accounts at the same time for the relativity of perception - the fact that an object appears differently when changing the circumstances of perception - and for perceptual constancy - the attribution of a certain qualitative property to an object, such as a specific shade of red in a homogeneously coloured region of the surface of the tomato. Furthermore, it can account for the fact that the same sensory qualities can be intentionally structured in different ways, as in the case of Gestalt figures, thus leading to the constitution of different perceptual objects (see Williford 2013: 508).

Therefore, in Husserl's phenomenology we already find, as in PIT, a view of perceptual intentionality in terms of constitution of objects on the basis of "narrow" contents of experiences. However, both in PIT and Husserl's phenomenology, this analysis of perception is situated on the "phenomenal level" (Farkas 2013: 108) and can be conceived of as metaphysically neutral, i.e. not committed to any specific view 
about the metaphysical nature of subject and object, mind and world - and therefore not committed to metaphysical views such as materialism, dualism, or idealism. ${ }^{19}$

At the same time, I have already stressed the relevance of the various theories of perception for the metaphysical investigation, because sense perception is a fundamental form of directedness of a subject of experience towards an (allegedly) "external world". ${ }^{20}$ For this reason, we can ask about the possible metaphysical implications of the account of perceptual intentionality as constitution of objects, in PIT and Husserl's phenomenology. However, doing so we are again faced with the problem of the external world, because this account of perception is compatible with scepticism concerning the existence of a mind-independent reality and is therefore compatible with subjective idealism, phenomenalism or solipsism. I will now argue that, by deepening the analysis of the temporal structure of perceptual intentionality, we can finally find a way out of this issue.

\subsection{Micro-temporality and genesis of intentionality}

At this point, I would like to show how investigating the micro-temporal structure of perceptual intentionality allows us to address the problem of the external world, by "deepening" the account of perception in terms of temporal structuring of qualities.

In fact, as I have already claimed, the analysis of perception as constitution by means of the intentional structuring of narrow phenomenal contents is focused on the temporality of perceptual experiences considered at a coarse-grained level. For example, I perceive a tomato by moving around it, thus looking at its various sides. Each "portion" of this perceptual process can be considered as a perceptual "state" that has a certain content (e.g. the quale "red" that is intentionally structured in order to constitute the perceptual experience of the tomato). In this coarsegrained analysis, the experiences that take part in the constitutive process are taken as given temporal units (Husserl 1983: 171). However, this is, in fact, another abstraction, since each of the moments of experience has a more finegrained temporal structure, being part of a continuous experiential flow. The analysis of this deeper temporal structure of experience is the topic of Husserl's "genetic phenomenology", which is centred on the analysis of time-consciousness (see Husserl 1991, 2001). According to Husserl, the investigation of the macrotemporal structure of experience - which he calls "static-descriptive" - has to be complemented by the "genetic-explicative" phenomenological method, which investigates what I am calling the micro-temporality of experience (Husserl 2001: 624). This fine-grained analysis of the temporality of experience sheds light on the "genesis of constitution" (Husserl 2001: 644), i.e. the process through

\footnotetext{
${ }^{19}$ Concerning the "metaphysical neutrality" of Husserl's phenomenology, I refer to the fact that from the onset it does not take a stance on metaphysical debates and that it is maybe compatible with various metaphysical positions (as argued e.g. by Yoshimi 2015). However, I will later claim that Husserl's genetic phenomenology can be complemented with a version of "neutral monism", which is a specific metaphysical position. This is a different sense of "neutrality" and I will propose it as a development of genetic phenomenology, rather than an interpretation of it. More on this below.

${ }^{20}$ Of course, this holds only if one thinks that it makes sense to ask about metaphysical questions in the first place.
} 
which the intentionality that constitutes objects is itself constituted in the first place. $^{21}$

Consider, for example, the perception of a melody. This perceptual process occurs over time and requires a continuous synthesis of momentary tones - "now" - in a unitary consciousness of the melody. The individual tones are qualitative components of a continuous flow of experience. In order to be aware of the melody in its entirety and not just of its momentary components, there must be at play a process of synthetic unification of the manifold tones. ${ }^{22}$ Husserl accounts for this phenomenon arguing that each tone occurring "now" is a "primal impression" that has to be "retained" in the flow of consciousness and has to be joined with the "protention" towards the tone that will come next. These "retentions" and "protentions" are functions that give structure to the qualitative contents and confer unity to the perception of the melody in its subjective and objectual sides, giving rise to what James (1890) calls the "specious present", i.e. a present that is not punctual but encompasses more than a singular moment in time. In this way, investigating the fine-grained temporal structure of perceptual intentionality we find a deeper level of the structuring of qualitative elements (the "primal impressions"). In other terms, in the light of this inquiry, the "phenomenal content" of intentional states turns out to be constituted itself out of a continuous qualitative flow (e.g. the flow of tones), which is structured by means of retentions and protentions. These structuring functions give unity to the series of experiences and give rise to perceptual intentionality.

Now, I would like to stress that, in Husserl's view, this is an account of conscious experience in general and not only of sense perception. In fact, the "primal impressions" are the qualities that constitute the "phenomenal character" of experience in all of its modalities. ${ }^{23}$ For instance, Husserl claims that also "a judging consciousness of a mathematical state of affairs is an impression" (Husserl 1991: 95/100) and that "belief is actual belief, is an impression." (Husserl 1991: 103/109). ${ }^{24}$ Furthermore, this view sheds light on the process through which both the object of experience and the subjective pole of experience are constituted at the same time. On this point, Husserl claims that genetic phenomenology investigates the genesis of what he calls "monadic individuality" (Husserl 2001: 635), referring with this expression to the concrete

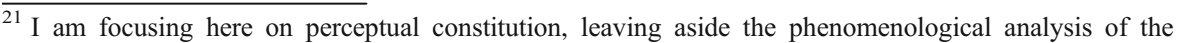
constitution of other "regions of being" and its relationship with the phenomenology of perception. Concerning the latter, Husserl claims that it is a fundamental form of "originarily presenting intuition" (Husserl 1983: 156) and develops its analysis in terms of constitution. I am not addressing here the question of whether and to what extent a similar analysis can be developed concerning other forms of intuition (e.g. empathy, moral perception or mathematical intuition). Also, I am not addressing the problem of the constitution of ideal objects in Husserl's phenomenology. In the end, it seems to me that the proposed account of perception and its development into a neutral monist metaphysics is compatible with Husserl's theory of essences and his doctrine of eidetic intuition, but a detailed analysis of this issue is matter for further inquiry (see also fn. 24, 25).

${ }^{22}$ As is known, this is the remark made by Kant to Hume's theory of experience as a succession of impressions. Kant claims that we must distinguish between the succession of impressions and the consciousness of this succession and argues that the latter requires a process of synthetic unification of the sensory manifold.

${ }^{23}$ On this point see Henry (2008: 23).

${ }^{24}$ In this way, Husserl anticipates a thesis that is dear to the proponents of so-called "cognitive phenomenology" (e.g. Pitt 2004). However, as I have said, I will not tackle here the complex issue of the ontological status of the objects of e.g. mathematical thinking, which are ideal objects. This is a matter for further inquiry.
} 
subject of experience. We can see this point by looking at the structure of perceptual experience: the fundamental process of structuring of qualities leads, at the same time, to the constitution of a certain object, e.g. the perceived melody, and of the subjective pole of the cognitive relation, i.e. the act of perceiving the melody. Perceiving the melody and the perceived melody turn out to be both grounded on the flow of primal qualities and on their structuring through retentions and protentions. In this way, the investigation of the temporal micro-structure of experience reveals a process of $\mathrm{co}^{-}$ constitution of subject and object of perceptual experience in reciprocal dependence: the process of constitution of objects is at the same time the process of constitution of perceptual acts, on the basis of a more fundamental process of structuring of primal qualities. This account can be extended from perceptual intentionality to "phenomenal intentionality" in general, i.e. the intentionality that is grounded on phenomenal character, thus constituting an account of the genesis of subject and object of experience in general. The idea is that all experiences, insofar as they are conscious "mental states" (e.g. episodes of thinking, imagining, desiring, feeling, etc.), involve a process of retention and protention of qualities by means of which the two poles of the experience are reciprocally constituted. ${ }^{25}$

In particular, this idea of the co-constitution of subject and object of experience is highlighted by those scholars who stress the relationist dimension of Husserl's phenomenology. According to Bernet, Husserl's phenomenology describes a form of "intentional interlacing of subject and object that precedes their separation and opposition" (Bernet 1994: 232). Gallagher and Zahavi also claim that in the phenomenological view "mind and world are not distinct entities, rather, they are bound constitutively together" (Gallagher and Zahavi 2012: 142). According to Zahavi, the investigation of experience in phenomenology "questions the very subject-object split" and stresses the "co-emergence of self and world" (Zahavi 2004: 58). Varela (1996: 339) also stresses that phenomenology seeks to move beyond the separation between subject and object, in order to reveal the fundamental correlation of the two poles of cognition. ${ }^{26,27}$

The qualitative relationism that I am here proposing is based on this view. I define qualitative relationism as, first of all, the view of perception that, in contrast to internalism and externalism, conceives of the two poles of perceptual experience as essentially correlated in a process of co-constitution that involves the retentional and protentional structuring of fundamental qualities. Extending this account to intentionality and experience in general, qualitative relationism conceives of the subject and object of experience as co-constituted out of qualities or "primal impressions".

\footnotetext{
${ }^{25}$ In my view, this account is not necessarily in contrast with the phenomenological doctrine of eidetic intuition, according to which individual beings have an essential nature that is known by means of an eidetic seeing (Husserl 1983: 9-10). Claiming that subjectivity and objectivity are co-constituted is still compatible with the idea that the experiencing subject has intuitive access to the essential structure of the various objective domains and to their essences. However, a detailed analysis of this issue is outside the scope of this paper (see Zhok (2012) for an useful analysis of the ontological status of essences in phenomenology).

${ }^{26}$ This idea is also at the basis of the enactive approach of (Varela, Thompson, and Rosch 1991), which takes from the Madhyamaka philosophy and from phenomenology the concept of the co-origination of subject and object, mind and world: "Knower and known, mind and world, stand in relation to each other through mutual specification or dependent coorigination." (Varela, Thompson, and Rosch 1991: 150).

${ }^{27}$ In these views, the epistemological and metaphysical plane are strictly related, since the co-constitution of subject and object of cognition is also understood as co-constitution of mind and world.
} 
However, at this point, we must ask: what are, exactly, the "primal impressions" that the genetic-phenomenological inquiry finds at the basis of the co-constitution of subject and object? The term "impression" seems to refer to something that is experienced by a subject, i.e. a phenomenal quality. In this way, the co-constitutive process would presuppose a more fundamental subject that has impressions. But this would make the problem of the external world even worse: by "deepening" the "internalist" view in PIT and phenomenology we would reach, in the end, a form of idealism. Is this the only option available? In the next section, I will explore an alternative to it.

\subsection{Neutral monism}

The alternative metaphysical option that I would like to propose now as a development of qualitative relationism is neutral monism. In this view, proposed first by Mach (1914), James (1912), and Russell (1921), there is an ultimate reality that is made up of qualitative elements and whose intrinsic nature is neither mental nor physical but neutral between the two. ${ }^{28}$ This qualitative and empiricist version of neutral monism has been also recently called panqualityism (Coleman 2015, 2016; see also Chalmers 2016a: 40-44; Goff 2017: 116) and it is carefully considered as a viable solution to the mind-body problem and to the "hard problem" of consciousness. ${ }^{29}$

In the light of this view, I propose to conceive of the qualitative elements that are at the heart of experience as fundamental qualities that are neutral to the distinction between subjective and objective, and therefore as pre-phenomenal qualities that are at the basis of the co-constitution of mental processes and objects. In this approach, the fundamental qualities are not yet phenomenal qualities of experience. They become the contents of experiences, correlated to objects, only under certain circumstances, when they combine into those complex entities that we call minds and physical objects. ${ }^{30}$

However, a classic objection to such a view is that the allegedly neutral elements are, in fact, mental entities, and that neutral monism is subjective idealism under disguise. This objection is also due to the fact that proponents of neutral monism often refer to neutral entities by using terms that refer to experiential qualities, such as sensations (Mach) and pure experiences (James). However, these are unfortunate terminological choices. Mach, who is the first proponent of this view, clarifies that he uses the term "sensation" to describe the neutral elements just because "most people are much more familiar with the elements in question as sensations (colours, sounds, pressures, spaces, times, etc.) (...)" (Mach 1914: 16). For this reason, scholars such as Parrini (2018) and Banks (2003) stress the fact that Mach's view is not subjective idealism or phenomenalism. The crucial point is that, in this view, both subjects and worldly objects are made up of complexes of neutral elements, but the elements can exist also independently of the cognitive relation (see Parrini 2018: 40). We can conceive of the basic qualitative elements as, first of all, "unsensed sensa" (Chalmers 2016a: 42) or

\footnotetext{
${ }^{28}$ This empiricist and qualitative version of neutral monism must be distinguished from other versions, such as Sayre's neutral monism of information (see Stubenberg 2018: 22).

${ }^{29}$ Nowadays, neutral monism is an object of renewed interest in philosophy of mind and metaphysics (see Banks 2003, 2010; Stubenberg 2018).

${ }^{30}$ This is a "neither view" of the neutrality of the elements and must be distinguished from a "both view", which claims that the basic entities are physical and mental at the same time (Stubenberg 2018: 3). The latter is better understood as a dual aspect monism or a form of panpsychism.
} 
"unexperienced qualia" (Coleman 2016: 249), i.e. "qualitative without being yet phenomenally qualitative (i.e. intrinsically conscious)." (Coleman 2015: 84) because "capable of existence outside of consciousness" (Coleman 2015: 69-70). Only under certain conditions can these qualities become the phenomenal contents of a subject's mental states and the qualities of objects. ${ }^{31}$

The most serious problem for this view is to account for how pre-phenomenal qualities can turn into the phenomenal contents of the experience of a subject. This is the so-called "combination problem" for panqualityism (Chalmers 2016b; Coleman 2016), which is due to the existence of a nonsubject/subject gap (Chalmers 2016a: 38). However, combining Husserl's genetic phenomenology with neutral monism can help us in addressing this problem. As we have seen, the phenomenological analysis of the "genesis of constitution" that is at the same time "genesis of monadic individuality" (i.e. genesis of the concrete conscious subject) sheds light on the process of coconstitution of subject and object. Combining this account with the neutral monist metaphysics, we can conceive of this process in terms of the structuring of prephenomenal qualities, conceived of as the fundamental constituents of reality. In this view, the structuring of these elements is the process through which a "phenomenal field", and therefore a subject of experience, comes to light, thus turning the fundamental qualities into phenomenal qualities (correlated, in turn, to objectual properties). ${ }^{32}$ As for the investigation of how this process of structuring of the fundamental qualities takes place, we can combine the phenomenology of time-consciousness with the findings of a phenomenologically-based neurobiology, following Varela's project of a neurophenomenology (Varela 1996, 1999). In Varela's view, we can investigate the biological counterparts of the structures of experience. In particular, it is possible to establish a correlation between the impressional-retentional-protentional dynamics of time-consciousness and certain neural processes (Varela 1999; Thompson 2007: 329 ff.), because the temporal structure of experience is "structurally mirrored at the biological level by the self-organising dynamics of large-scale neural activity" (Thompson 2007: 329).

Varela conceived of this view as a way of "naturalizing phenomenology", without, however, developing it into a metaphysical position. ${ }^{33}$ On the contrary, I suggest to develop neurophenomenology within a neutral monist framework. In this view, the biological domain is made up of complexes of neutral elements (i.e. pre-phenomenal

\footnotetext{
${ }^{31}$ This point marks the difference between the qualitative version of neutral monism (or panqualityism) and panpsychism. Chalmers (2016a) defines panqualityism as a version of panprotopsychism (i.e. the view that fundamental entities are not conscious per se but are precursors to consciousness).

${ }^{32}$ I have to clarify that this is the proposal of a possible development of Husserl's genetic phenomenology and not strictly an interpretation of it. That is, I am not claiming that, in the end, Husserl was a neutral monist. It may well be that, in the end, he was a metaphysical idealist (as claimed e.g. by Yoshimi 2015) or that he remained faithful to the "metaphysical neutrality" of phenomenology (in the sense that phenomenology is not committed to any metaphysical view). I am just suggesting that neutral monism is a viable way of developing genetic phenomenology that is worthy of being considered.

${ }^{33}$ In fact, Varela proposes neurophenomenology as a "methodological remedy" to the hard problem of consciousness (Varela 1996) that, in continuity with the enactive approach of (Varela, Thompson, and Rosch 1991), does not have any metaphysical commitment (this "anti-metaphysical” aspect of Varela's view and of the original version of enactivism is highlighted for instance by (Vörös et al. 2016; Bitbol 2012; Bitbol and Antonova 2016).
} 
qualities), which, when they acquire a certain structure - investigated by neuroscience and phenomenology - give rise to a field of consciousness. ${ }^{34}$

\section{Conclusion}

In the first two sections of this paper, we have seen the two main views concerning the sensory qualities of perception: quality externalism and quality internalism. In my view, qualitative relationism constitutes an alternative to these views that can overcome their respective difficulties, at the same time maintaining some of their opposite virtues. By distinguishing between two levels in the investigation of the temporality of experience, we can admit that, within the macro-temporal level of inquiry, qualities appear at the same time as phenomenal properties of mental states and sensible properties of perceptual objects. In fact, common sense and ordinary language refer, depending on the case, both to qualities of objects (e.g. the redness of the tomato) and sensations and qualitative appearances (e.g. redsensations in the case of afterimages or other anomalous situations, plus those phenomenal states such as pains and moods that do not seem to pertain to mind-independent objects in the world). A virtue of qualitative relationism is that it can maintain both characterizations of qualities (as "internal" and as "external"), without forcing us to choose one at the expense of the other. This is because, at the same time, we can admit, within the qualitative relationist view, a more fundamental qualitative dimension that grounds the two poles of the perceptual relation. Considering, for instance, the case of colour, in the qualitative relationist view, "redness", when considered at the micro-temporal level, is a primal qualitative process out of which the relation between "sensation of red" and "perceived redness of the object" are correlated and co-constituted, when certain qualitative elements are combined in the reciprocal constitution of perceiver and perceived.

In this way, qualitative relationism is able to better address the respective problems of quality externalism and internalism. Concerning the problem of perception, it can unitarily account for veridical perception, perspectival variation, illusion and hallucination, claiming that in all of these cases the same process is taking place, i.e. a flow of qualities. This qualitative flow can give rise, depending on the case, to veridical perceptions, illusions, and hallucinations. In this account, the difference between these experiences is not in their qualitative content but in their different macro-temporal structuring. What we call an "external" object is constituted as correlate of a series of experiences that are concordant and motivated one by the other, ${ }^{35}$ in contrast to those experiences in which the experiential synthesis is deficient. It is the coherence between a series of experiences that testifies the "external" status of the object which, however, is itself constituted by sets of qualitative elements. ${ }^{36}$

\footnotetext{
34 The following passages from Mach (1914) help to illustrate this proposal: "bodies do not produce sensations, but complexes of elements (complexes of sensations) make up bodies", "all bodies are but thought-symbols for complexes of elements", and "the elements in question form the real, immediate, and ultimate foundation, which it is the task of physiologico-physical research to investigate" (Mach 1914: 29).

${ }^{35}$ On the concept of motivation see Husserl (1989: 62).

${ }^{36}$ An issue that I have just mentioned in the introduction concerns how to account, within this framework, for unconscious cognitive states. This would require a detailed analysis, but I don't see problems, in principle, in addressing it within the proposed framework, since these phenomena can be analyzed in the same way as other physiological processes (e.g. digestion, which is a bodily process of which I am mostly not aware of).
} 
Concerning the problem of the external world and the possibility of solipsism, the development of qualitative relationism as a form of neutral monism has the advantage of being positioned beyond the alternative idealism-materialism. This is because it admits the existence of a primal dimension of reality that precedes the dualities of subject-object, internal-external, mind-world. In doing so, it can avoid the solipsist hypothesis, which implies that one of the two poles of the subject-object relation is an absolute domain that is enclosed in itself. On the contrary, according to this view, subject and object refer to each other, being essentially correlated in a process of reciprocal constitution out of fundamental qualities.

Acknowledgments I would like to thank Philipp Berghofer, Krys Dolega, Alberto Peruzzi, Tobias Starzak, Elmarie Venter, Alfredo Vernazzani and Silvano Zipoli Caiani for useful comments on earlier drafts of this paper. I would also like to thank an anonymous reviewer for some valuable comments which helped me to elaborate and refine this paper in various points. This work was supported by grants from the Deutsche Akademische Austauschdienst (DAAD, Annual Research Grant) and from the Österreichischer Austauschdienst (OeAD, Ernst Mach Grant).

\section{Availability of data and material Not applicable.}

Authors' contributions Not applicable.

Funding Open access funding provided by Università degli Studi di Firenze within the CRUI-CARE Agreement. This work was supported by grants from the Deutsche Akademische Austauschdienst (DAAD, Annual Research Grant at the Department of Philosophy II, Center for Mind and Cognition, Ruhr-Universität Bochum) and from the Österreichischer Austauschdienst (OeAD, Ernst Mach Grant at the Department of Philosophy, University of Graz).

\section{Compliance with ethical standards}

Conflicts of interest/competing interests No potential conflict of interest.

Code availability Not applicable.

Open Access This article is licensed under a Creative Commons Attribution 4.0 International License, which permits use, sharing, adaptation, distribution and reproduction in any medium or format, as long as you give appropriate credit to the original author(s) and the source, provide a link to the Creative Commons licence, and indicate if changes were made. The images or other third party material in this article are included in the article's Creative Commons licence, unless indicated otherwise in a credit line to the material. If material is not included in the article's Creative Commons licence and your intended use is not permitted by statutory regulation or exceeds the permitted use, you will need to obtain permission directly from the copyright holder. To view a copy of this licence, visit http://creativecommons.org/licenses/by/4.0/.

\section{References}

Banks, E. C. (2003). Ernst Mach's world elements. A study in natural philosophy. Dordrecht: Springer.

Banks, E. C. (2010). Neutral monism reconsidered. Philosophical Psychology, 23(2), 173-187.

Bernet, R. (1994). An intentionality without subject or object? Man and World, 27(3), 231-255.

Bitbol, M. (2012). Neurophenomenology, an ongoing practice of/in consciousness. Constructivist Foundations, 7(3), 165-173. 
Bitbol, M., \& Antonova, E. (2016). On the too often overlooked radicality of neurophenomenology. Constructivist Foundations, 11(2), 354-356.

Bourget, D. \& Mendelovici, A. (2017). Phenomenal intentionality. In Stanford encyclopedia of philosophy. Metaphysics Research Lab, CSLI, Stanford University.

Chalmers, D. J. (1996). The conscious mind. Oxford: Oxford University Press.

Chalmers, D. J. (2016a). Panpsychism and panprotopsychism. In G. Bruntrup \& L. Jaskolla (Eds.), Panpsychism: Contemporary perspectives (pp. 19-47). New York: Oxford University Press.

Chalmers, D. J. (2016b). The combination problem for panpsychism. In G. Bruntrup \& L. Jaskolla (Eds.), Panpsychism: Contemporary perspectives (pp. 179-214). New York: Oxford University Press.

Cohen, J. (2004). Color properties and color ascriptions: A relationalist manifesto. The Philosophical Review, $113(4), 451-506$.

Coleman, S. (2015). Neuro-cosmology. In P. Coates \& S. Coleman (Eds.), Phenomenal qualities: Sense, perception, and consciousness (pp. 66-102). Oxford: Oxford University Press.

Coleman, S. (2016). Panpsychism and neutral monism: How to make up one's mind. In G. Bruntrup \& L. Jaskolla (Eds.), Panpsychism: Contemporary perspectives (pp. 249-282). New York: Oxford University Press.

Crane, T., \& French, C. (2017). The problem of perception. In Stanford encyclopedia of philosophy. Metaphysics Research Lab, CSLI, Stanford University.

Descartes, R. (2008). Meditations on first philosophy. Edited by Michael Moriarty. Oxford: Oxford University Press.

Dretske, F. (1995). Naturalizing the mind. Cambridge: The MIT Press.

Dretske, F. (1996). Phenomenal externalism or if meanings ain't in the head, where are qualia? Philosophical Issues, 7(Perception), 143-158.

Dretske, F. (2003). Experience as representation. Philosophical Issues, 13(Philosophy of Mind), 67-82.

Farkas, K. (2003). What is externalism? Philosophical Studies, 112(3), 187-208.

Farkas, K. (2008). Phenomenal intentionality without compromise. The Monist, 91(2), 273-293.

Farkas, K. (2013). Constructing a world for the senses. In U. Kriegel (Ed.), Phenomenal intentionality (pp. 99114). Oxford: Oxford University Press.

Gallagher, S., \& Zahavi, D. (2012). The phenomenological mind. An introduction to philosophy of mind and science (2nd edn.). London - New York: Routledge.

Gibson, J. J. (1966). The senses considered as perceptual systems. Boston: Houghton Mifflin.

Gibson, J. J. (1967). New reasons for realism. Synthese, 17(2), 162-172.

Gibson, J. J. (1972). A theory of direct visual perception. In J. R. Royce \& W. W. Rozeboom (Eds.), The psychology of knowing. New York: Gordon \& Breach.

Goff, P. (2017). Panpsychism. In The S. Schneider \& M. Velmans (Eds.), The Blackwell companion to consciousness (2nd edn., pp. 106-124). Wiley.

Gow, L. (2018). Why externalist representationalism is a form of disjunctivism. Ratio, 31(1), 35-50.

Heft, H. (2001). Ecological psychology in context. James Gibson, Roger Barker, and the legacy of William James's radical empiricism. Lawrence Erlbaum Associates.

Henry, M. (2008). Material phenomenology. New York: Fordham University Press.

Horgan, T., \& Tienson, J. (2002). The intentionality of phenomenology and the phenomenology of intentionality. In D. J. Chalmers (Ed.), Philosophy of mind: Classical and contemporary readings (pp. 520533). Oxford: Oxford University Press.

Horgan, T., Tienson, J., \& Graham, G. (2004). Phenomental intentionality and the brain in a vat. In R. Schantz (Ed.), The Externalist Challenge: New Studies on Cognition and Intentionality (pp. 297-318). Amsterdam: Walter de Gruyter.

Husserl, E. (1983). Ideas pertaining to a pure phenomenology and to a phenomenological philosophy. First book: General introduction to a pure phenomenology. Edited by F. Kersten. The Hague: Martinus Nihoff.

Husserl, E. (1989). Ideas pertaining to a pure phenomenology and to a phenomenological philosophy. Second book: Studies in the phenomenology of constitution. Edited by Richard Rojcewicz and André Schuwer. Dordrecht: Kluwer Academic Publishers.

Husserl, E. (1991). On the phenomenology of the consciousness of internal time (1893-1917). Edited by John Barnett Brough. Dordrecht: Kluwer Academic Publishers.

Husserl, E. (2001). Analyses concerning passive and active synthesis: Lectures on transcendental logic. Edited by Anthony J. Steinbock. Dordrecht: Springer.

James, W. (1890). The principles of psychology. New York: Dover.

James, W. (1912). Essays in radical empiricism. New York: Longman Green \& Co..

Kriegel, U. (2007). Intentional inexistence and phenomenal intentionality. Philosophical Perspectives, 21(1), 307-340. 
Kriegel, U. (2013). The phenomenal intentionality research program. In U. Kriegel (Ed.), Phenomenal intentionality. Oxford: Oxford University Press.

Loar, B. (2003). Phenomenal intentionality as the basis of mental content. In M. Hahn \& B. Ramberg (Eds.), Reflections and replies: Essays on the philosophy of Tyler Burge (pp. 229-258). Cambridge: MIT Press.

Mach, E. (1914). The analysis of sensations, and the relation of the physical to the psychical. Chicago and London: The Open Court Publishing Company.

Masrour, F. (2013). Phenomenal objectivity and phenomenal intentionality. In defense of a Kantian account. In U. Kriegel (Ed.), Phenomenal intentionality (pp. 116-34). Oxford: Oxford University Press.

Mcintyre, R. (1999). Naturalizing phenomenology? Dretske on qualia. In J. Petitot, F. J. Varela, J.-M. Roy, \& B. Pachoud (Eds.), Naturalizing phenomenology: Issues in contemporary phenomenology and cognitive science (pp. 429-439). Stanford: Stanford University Press.

Nagel, T. (1974). What is it like to be a bat? Philosophical Review, 83(October), 435-450.

Parrini, P. (2018). Ernst Mach and the disenchantment of metaphysics. In P. Gori (Ed.), Ernst Mach tra scienza e filosofia (pp. 33-52). Pisa: ETS.

Petitot, J., \& Smith, B. (1997). Physics and the phenomenal world. In R. Poli \& P. M. Simons (Eds.), Formal ontology (pp. 233-254). Dordrecht: Kluwer.

Pitt, D. (2004). The phenomenology of cognition or what is it like to think that P? Philosophy and Phenomenological Research, 69(1), 1-36.

Russell, B. (1921). The analysis of mind. London: George Allen \& Unwin.

Smith, B. (1995). The structures of the common-sense world. Acta Philosophica Fennica, 58, 290-317.

Smith, B. (1999). Truth and the visual field. In J. Petitot, F. J. Varela, B. Pachoud, \& J.-M. Roy (Eds.), Naturalizing phenomenology: Issues in contemporary phenomenology and cognitive science (pp. 317329). Stanford: Stanford University Press.

Stubenberg, L. (2018). Neutral Monism. In Stanford encyclopedia of philosophy. Metaphysics Research Lab, CSLI, Stanford University.

Thompson, E. (2007). Mind in life: Biology, phenomenology and the sciences of mind. Cambridge: Harvard University Press.

Tye, M. (1995). Ten problems of consciousness. A representational theory of the phenomenal mind. Cambridge: MIT Press.

Varela, F. J. (1996). Neurophenomenology. A methodological remedy for the hard problem. Journal of Consciousness Studies, 3(4), 330-349.

Varela, F. J. (1999). The specious present: A Neurophenomenology of time consciousness. In J. Petitot, F. J. Varela, B. Pachoud, \& J.-M. Roy (Eds.), Naturalizing phenomenology: Issues in contemporary phenomenology and cognitive science (pp. 266-314). Stanford: Stanford University Press.

Varela, F. J., Thompson, E., \& Rosch, E. (1991). The embodied mind: Cognitive science and human experience. Cambridge: MIT Press.

Vörös, S., Froese, T., \& Riegler, A. (2016). Epistemological odyssey. Introduction to special issue on the diversity of enactivism and neurophenomenology. Constructivist Foundations, 11(2), 189-203.

Williford, K. (2013). Husserl's hyletic data and phenomenal consciousness. Phenomenology and the Cognitive Sciences, 12(3), 501-519.

Yoshimi, J. (2015). The metaphysical neutrality of Husserlian phenomenology. Husserl Studies, 31(1), 1-15.

Zahavi, D. (2004). Husserl's noema and the internalism-externalism debate. Inquiry, 47(1), 42-66.

Zhok, A. (2012). The ontological status of essences in Husserl's thought. New Yearbook for Phenomenology and Phenomenological Philosophy, XI, 99-130.

Publisher's note Springer Nature remains neutral with regard to jurisdictional claims in published maps and institutional affiliations. 